\title{
Frying quality and stability of high-oleic Moringa oleifera seed oil in comparison with other vegetable oils
}

\begin{abstract}
The performance of the high-oleic Moringa oleifera seed oil (MoO) in deep-frying was evaluated by comparing its frying stability with other conventional frying oils [canola (CLO), soybean (SBO), and palm olein (PO)]. The oils were used as a frying media to fry potato chips for $6 \mathrm{~h}$ a day up to a maximum of 5 days. Standard methods for the determination of used frying oil deterioration such as changes in color, viscosity, free fatty acids (FFA), peroxide value (PV), p-anisidine value (p-AV), iodine value (IV), specific extinction $(\mathrm{E} \mid \mathrm{cm}$ $\% 233$ and $269 \mathrm{~nm}$ ) and total polar compounds (TPC) were used to evaluate the oils. At the end of the frying period, the change in percent FFA from the initial to final day of frying were as follows SBO (60.0\%), PSO (65.0\%), MoO (66.6\%) and CLO (71.4\%) and the change in $\mathrm{p}-\mathrm{AV}$ and TOTOX value of $\mathrm{MoO}$ were found to be significantly lower $(\mathrm{P}<0.05)$ than the rest of the oils tested, followed by PO, with the highest values obtained in CLO and SBO. The levels of conjugated dienes and trienes (E $\mid \mathrm{cm} \%$ at 233 and $269 \mathrm{~nm}$ ) throughout the frying period were lowest in $\mathrm{MoO}$ and PO followed CLO, with highest levels found in SBO. The rate of darkening and increase in viscosity were proportional to the frying time for all the oils. PO darkened earlier followed by CLO. At the end of frying period, TPC was significantly $(\mathrm{P}<0.05)$ lower in $\mathrm{MoO}(20.78 \%)$ and PSO $(21.23 \%)$, as compared to CLO $(28.73 \%)$ and SBO (31.82\%).
\end{abstract}

Keyword: High-oleic Moringa oleifera seed oil; Oxidative stability; Frying quality 